\title{
Duration of prone position sessions: a prospective cohort study
}

\author{
Sebastien Jochmans ${ }^{1,2^{*}} \mathbb{D}$, Sandie Mazerand ${ }^{1}$, Jonathan Chelly ${ }^{1,2}$, Franck Pourcine ${ }^{1}$, Oumar Sy ${ }^{1}$, \\ Nathalie Thieulot-Rolin', Olivier Ellrodt ${ }^{1}$, Emmanuelle Mercier Des Rochettes ${ }^{1,3}$, Gaël Michaud ${ }^{1}$, \\ Jean Serbource-Goguel ${ }^{1}$, Christophe Vinsonneau ${ }^{1,2,4}$, Ly Van Phach Vong ${ }^{1}$ and Mehran Monchi ${ }^{1,2}$
}

\begin{abstract}
Background: Prone position (PP) is highly recommended in moderate-to-severe ARDS. However, the optimal duration of PP sessions remains unclear. We searched to evaluate the time required to obtain the maximum physiological effect, and to search for parameters related to patient survival in PP.

Methods and results: It was a prospective, monocentric, physiological study. We included in the study all pronepositioned patients in our ICU between June 2016 and January 2018. Pulmonary mechanics, data from volumetric capnography and arterial blood gas were recorded before prone positioning, $2 \mathrm{~h}$ after proning, before return to a supine position (SP) and $2 \mathrm{~h}$ after return to SP. Dynamic parameters were recorded before proning and every $30 \mathrm{~min}$ during the session until $24 \mathrm{~h} .103$ patients (ARDS 95\%) were included performing $231 \mathrm{PP}$ sessions with a mean length of $21.5 \pm 5 \mathrm{~h}$ per session. They presented a significant increase in $\mathrm{pH}$, static compliance and $\mathrm{P}_{\mathrm{a}} \mathrm{O}_{2} / \mathrm{F}_{i} \mathrm{O}_{2}$ with a significant decrease in $\mathrm{P}_{\mathrm{a}} \mathrm{CO}_{2}, \mathrm{P}_{\text {plat, }}$ phase 3 slope of the volumetric capnography, $\mathrm{P}_{\mathrm{et}} \mathrm{CO}_{2}, V_{\mathrm{D}} / V_{\mathrm{T} \text {-phy }}$ and $\triangle P$. The beneficial physiological effects continued after $16 \mathrm{~h}$ of PP and at least up to $24 \mathrm{~h}$ in some patients. The evolution of the respiratory parameters during the first session and also during the pooled sessions did not find any predictor of response to $\mathrm{PP}$, whether before, during or $2 \mathrm{~h}$ after the return in $\mathrm{SP}$.
\end{abstract}

Conclusions: PP sessions should be prolonged at least $24 \mathrm{~h}$ and be extended in the event that the $\mathrm{P}_{2} \mathrm{O}_{2} / \mathrm{F}_{1} \mathrm{O}_{2}$ ratio at $24 \mathrm{~h}$ remains below 150, especially since no criteria can predict which patient will benefit or not from it.

Trial registration The trial has been registered on 28 June 2016 in ClinicalTrials.gov (NCT 02816190) (https://clinicaltrials. gov/ct2/show/NCT02816190?term=propocap\&rank=1).

Keywords: Prone position, Acute respiratory distress syndrome, Capnography, Protective ventilation, Mechanical ventilation, Acute respiratory failure

\section{Background}

Prone position (PP) has been part of respiratory management of moderate-to-severe acute respiratory distress syndrome (ARDS) for several years [1]. Randomized controlled trials have confirmed that oxygenation is improved in the PP compared to the supine position (SP) [2-6]. It could also prevent ventilator-induced lung injury

\footnotetext{
*Correspondence: sebastien.jochmans@gmail.com

1 Département de Médecine Intensive-Réanimation, GH Sud Ile-de-

France, Hôpital de Melun, 270 avenue Marc Jacquet, 77000 Melun, France
}

Full list of author information is available at the end of the article
(VILI). It would reduce pulmonary stress and strain by reducing the overdistension of aerated non-dependent zones while allowing recruitment of atelectatic dependent zones [7-10]. The compliance of the respiratory system would increase [11] despite a decrease in the compliance of the chest wall [12]. Lung expansion would be more homogeneous with improved ventilation/perfusion ratios and reduced VILI [13-16].

Two meta-analyses $[17,18]$ and then the PROSEVA trial [6] showed a beneficial effect on the outcome of moderate-to-severe ARDS with a reduction in mortality. $\mathrm{PP}$ is thus one of the three therapeutics to have shown 
a positive effect on ARDS mortality, with the reduction of the tidal volume (VT) [19] and the early use of neuromuscular blocking agents (NMBA) [20], although this is partly challenged by a recent study [21,22]. This is why its use is highly recommended in severe ARDS [23, 24]. Its use in mild-to-moderate ARDS remains debated [25].

However, the optimal duration of PP sessions remains unclear. International recommendations are to leave the patient in PP for at least $12 \mathrm{~h} \mathrm{[23].} \mathrm{In} \mathrm{the} \mathrm{PROSEVA} \mathrm{trial}$ [6], they stayed on average $17 \mathrm{~h}$, while the meta-analyses included studies with sessions lasting from 7 to $18 \mathrm{~h}$.

We conducted a prospective monocentric physiological study, including all patients put in PP. The main objective was to evaluate the time sufficient to obtain the maximum improvement in several physiological respiratory parameters in the first PP session and in all PP sessions. The secondary objective was to search for physiological parameters related to patient survival in PP.

\section{Materials and methods}

It was a prospective, monocentric, physiological study. We included in the study all prone-positioned patients in our intensive care unit (ICU) between June 2016 and January 2018. PP was indicated in case of moderate-tosevere hypoxemia with $\mathrm{P}_{\mathrm{a}} \mathrm{O}_{2} / \mathrm{F}_{\mathrm{i}} \mathrm{O}_{2}<150$ despite a set PEEP of at least $10 \mathrm{cmH}_{2} \mathrm{O}$ and the use of NMBA. The sessions were to last from 16 to $24 \mathrm{~h}$ or more. PP was not performed in case of severe hemodynamic instability (life-threatening cardiac arrhythmia, vasopressor $>2 \mu \mathrm{g} /$ $\mathrm{kg} / \mathrm{min}$ ) or withdrawal of life sustaining treatments. The PP procedure was completely protocolized (protocol available in Additional file 1). The sessions could be interrupted before $16 \mathrm{~h}$ in case of urgent care (CT, surgery, cardiac arrest, etc.). Otherwise the return to the supine position was made after at least $16 \mathrm{~h}$, if $\mathrm{P}_{\mathrm{a}} \mathrm{O}_{2} / \mathrm{F}_{\mathrm{i}} \mathrm{O}_{2}>150$ and if the staff was completely available. Prone position therapy was stopped when $\mathrm{P}_{\mathrm{a}} \mathrm{O}_{2} / \mathrm{F}_{\mathrm{i}} \mathrm{O}_{2}$ remained above 150 in SP. Mechanical ventilation was delivered in a controlled ventilation mode, either in volume or in pressure. Expiratory tidal volume $\left(\mathrm{VT}_{\mathrm{e}}\right)$ had to be adjusted between 5 and $8 \mathrm{~mL} / \mathrm{kg}$ of predicted body weight. PEEP was set to achieve an end-inspiratory plateau pressure $\left(\mathrm{P}_{\text {plat }}\right)$ between 28 and $30 \mathrm{cmH}_{2} \mathrm{O}$ (or more if an esophageal pressure probe was used to titrate PEEP according to inspiratory and/or expiratory transpulmonary pressure) [26]. Respiratory rate (RR) was set to maintain an arterial plasma pH of 7.20 to 7.45 without an increase in intrinsic PEEP.

Extracorporeal membrane oxygenation technics (ECMO) were proposed after at least $12 \mathrm{~h}$ of PP for persistent $\mathrm{P}_{\mathrm{a}} \mathrm{O}_{2} / \mathrm{F}_{\mathrm{i}} \mathrm{O}_{2}<60$ or respiratory acidosis $(\mathrm{pH}<7.2)$, despite hemodynamic optimization and PEEP adjusted according to esophageal pressure. The ARDS should not last more than 7 days. And the patient also had to be stable enough to support the transfer because our center did not perform ECMO.

In the supine position, the head was elevated between $30^{\circ}$ and $45^{\circ}$. In the prone position, the head was elevated between $10^{\circ}$ and $20^{\circ}$. Recruitment maneuvres were performed only in case of de-recruiting event (ventilator disconnection, bronchoscopy, prolonged tracheal suctioning, etc.), with a 15-s inspiratory pause at $30 \mathrm{cmH} 2 \mathrm{O}$.

All patients had an arterial line catheter. They were ventilated with a Hamilton S1 ventilator (Hamilton Medical $A G^{\circledR}$, Bonaduz, Switzerland) equipped with a dedicated proximal pneumotachometer and a dedicated main stream volumetric capnography sensor $\left(\right.$ Capnostat $-5^{\circledR}$, Hamilton Medical AG ${ }^{\circledR}$, Bonaduz, Switzerland). Pulmonary mechanics, data from volumetric capnography and arterial blood gas were recorded before prone positioning, $2 \mathrm{~h}$ after proning, before return in SP and $2 \mathrm{~h}$ after return in SP. Static values were recorded and calculated at these steady-state periods. Additionally end-tidal $\mathrm{CO}_{2}$ pressure $\left(\mathrm{P}_{\mathrm{et}} \mathrm{CO}_{2}\right)$, dynamic compliance $\left(\mathrm{C}_{\mathrm{dyn}}\right), \mathrm{VT}_{\mathrm{e}}$, physiological Bohr dead space $\left(V_{\mathrm{D}} / V_{\mathrm{T}-\text { phy }}\right)$ and phase 3 slope of the volumetric capnography $\left(\mathrm{S}_{\mathrm{III}}\right)$ were recorded before proning and every $30 \mathrm{~min}$ during the PP session (until $24 \mathrm{~h}$ of PP). $\mathrm{S}_{\mathrm{III}}$ of volumetric capnography is a plateau phase corresponding to the emptying of the alveolar compartment. The more flat the slope (i.e., close to 0), the more the alveoli have a simultaneous emptying and an identical $\mathrm{CO}_{2}$ concentration (therefore similar ventilation/perfusion ratios). The increase in the slope will thus be associated with a desynchronization of the alveolar emptying and/or an increase in the inhomogeneity of the ventilation/perfusion ratios [27]. Dynamic driving pressure $\left(\Delta P_{\text {dyn }}\right)$ was calculated by $\mathrm{VT}_{\mathrm{e}} / \mathrm{C}_{\mathrm{dyn}}$.

Baseline characteristics at the inclusion were recorded: age, gender, body mass index, severity scores (SAPS 2 and SOFA), ARDS (according to Berlin definition) [28] and the etiology of acute respiratory failure. The number of PP sessions and their lengths were recorded. Associated ICU main treatments (length of mechanical ventilation, use (at any time) of non-invasive ventilation, vasopressors, tracheostomy, renal replacement therapy, extracorporeal membrane oxygenation, corticosteroids and NMBA) were detailed as well as patients' outcomes.

Wilcoxon matched pairs rank tests were performed to compare patients' characteristics before PP, $2 \mathrm{~h}$ after PP, before SP and $2 \mathrm{~h}$ after SP. To evaluate time effect, responder sessions were defined as the change between baseline value and end session value (before return in SP), greater than or less than $0 \%$ according to the expected physiological effect (e.g., $\mathrm{C}_{\mathrm{dyn}}$-responder sessions were assessed by $\Delta C_{\mathrm{dyn}}>0 \% ; \Delta P_{\mathrm{dyn}}$ responder sessions were assessed by $\left.\Delta \Delta P_{\mathrm{dyn}}<0 \% \ldots\right)$. Each PP session 
could be a responder session for one parameter, independently of the response to other parameters. All sessions were analyzed with the parameters collected every 30 min: $\mathrm{P}_{\text {et }} \mathrm{CO}_{2}, \mathrm{C}_{\mathrm{dyn}}, V_{\mathrm{D}} / V_{\mathrm{T}-\mathrm{phy}}, \mathrm{S}_{\mathrm{III}}$ and $\Delta P_{\mathrm{dyn}}$. For the secondary objective, data from the first PP session were compared between survivors and deaths. Mann-Whitney and Fisher exact tests were used to compare patients' characteristics according to their vital status on hospital discharge. We also performed multivariate logistic regression analyses with mortality as the dependent variable. We analyzed data from the first PP session and the effect on the main responding physiological parameters for each patient. The regression models were then tested by Hosmer and Lemeshow goodness-of-fit test. Statistical analyses were performed with Prism 6 (GraphPad Software Inc ${ }^{\circledR}$, San Diego, CA, USA) and SPSS Statistics V20 (IBM ${ }^{\circledR}$, New York, NY, USA).

The study protocol has been approved by the Institutional Review Board of the French learned society for respiratory medicine (Société de Pneumologie de Langue Française) in accordance with the ethical standards laid down in the 1964 Declaration of Helsinki and its later amendments. Patients, or their relatives, have consented to the use of the data. The trial has been recorded in ClinicalTrials.gov (NCT 02816190).

\section{Results}

112 patients were eligible for inclusion. 9 were not included because of severe hemodynamic compromise $(n=5)$, missing data at inclusion $(n=3$; one of which was transferred early for ECMO) and therapeutic limitation decision $(n=1) .103$ patients were included performing $231 \mathrm{PP}$ sessions (2.2 $\pm 1.8 \mathrm{PP}$ sessions per patient) with a mean length of $21.5 \pm 5 \mathrm{~h}$ per PP session. 10 (4.3\%) PP sessions were interrupted before $16 \mathrm{~h}$ and only $2(0.8 \%)$ before $12 \mathrm{~h}$ (one for surgery, one for cardiac arrest). The longest session lasted $41.5 \mathrm{~h}$. Baseline characteristics at inclusion, main ICU treatments, complications during ICU care and outcomes are summarized in Table 1 . These were mainly severe patients (SAPS $2=54 \pm 17$ ) with ARDS (95\%) due to pneumonia (93.2\%) and with septic shock (98.1\%). 5 (5\%) patients were prone positioned for acute hypoxemic failure due to unilateral pneumonia. Virtually all patients were paralyzed (94.2\%). 38 patients died in ICU (36.9\%) and 39 (37.9\%) during hospital stay. Complications specifically related to PP have not been systematically collected. However, there were no serious complications: no tearing of catheters or tracheal tubes. One cardiac arrest was noted during the PP, occurring in an already moribund patient before the reversal. Complications were limited to pressure sores and occasional transient airway obstructions occurring just after the PP maneuver.

\begin{tabular}{|c|c|}
\hline Patients' variables & Values \\
\hline \multicolumn{2}{|l|}{ Inclusion } \\
\hline N & 103 \\
\hline Age (years) & $60 \pm 13(58-63)$ \\
\hline Male gender $(n)$ & $73(70.9 \%)$ \\
\hline $\mathrm{BMI}\left(\mathrm{kg} / \mathrm{m}^{2}\right)$ & $29 \pm 7(28-31)$ \\
\hline SAPS2 & $54 \pm 17(51-57)$ \\
\hline SOFA & $9 \pm 4(9-10)$ \\
\hline $\operatorname{ARDS}(n)$ & $98(95 \%)$ \\
\hline ARDS due to pneumonia $(n)$ & $96(93.2 \%)$ \\
\hline \multicolumn{2}{|l|}{ ICU stay } \\
\hline Prone position sessions ( $n$ ) & 231 \\
\hline Prone position sessions ( $n$ per patient) & $2.2 \pm 1.8(1.9-2.6)$ \\
\hline Prone position sessions (hours) & $21.5 \pm 5(20.7-22)$ \\
\hline Delay between sessions (hours) & $64.2 \pm 99.2(37.3-91.2)$ \\
\hline Invasive mechanical ventilation (days) & $17.3 \pm 10.9(15.2-19.4)$ \\
\hline Non-invasive ventilation $(n)^{\mathrm{a}}$ & $73(70.9 \%)$ \\
\hline Non-invasive ventilation (days) ${ }^{\mathrm{a}}$ & $3.2 \pm 2.6(2.6-3.8)$ \\
\hline Vasopressor $(n)^{\mathrm{a}}$ & $101(98.1 \%)$ \\
\hline Vasopressor duration (days) ${ }^{a}$ & $9 \pm 7.3(7.6-10.5)$ \\
\hline Tracheostomy $(n)^{\mathrm{a}}$ & $10(9.7 \%)$ \\
\hline Renal replacement therapy $(n)^{\mathrm{a}}$ & $29(34 \%)$ \\
\hline Corticosteroids $(n)^{\mathrm{a}}$ & $68(66 \%)$ \\
\hline $\operatorname{NMBA}(n)^{\mathrm{a}}$ & $97(94.2 \%)$ \\
\hline Extracorporeal membrane oxygenation $(n)^{\mathrm{a}}$ & $1(1 \%)$ \\
\hline \multicolumn{2}{|l|}{ Complications and outcomes } \\
\hline Pneumothorax $(n)^{\mathrm{a}}$ & $2(1.9 \%)$ \\
\hline Ventilation-associated pneumonia $(n)^{\mathrm{a}}$ & $44(49.7 \%)$ \\
\hline ICU length of stay (days) & $22.3 \pm 13.8(19.6-24.9)$ \\
\hline Hospital length of stay (days) & $27.2 \pm 15.5(24.2-30.1)$ \\
\hline ICU deaths with ARDS ( $n)$ & $34(33 \%)$ \\
\hline ICU deaths $(n)$ & $38(36.9 \%)$ \\
\hline Hospital deaths $(n)$ & $39(37.9 \%)$ \\
\hline
\end{tabular}

Values are expressed with $\mathrm{n}(\%)$ or mean \pm SD (95\% confidence interval) $B M I$ body mass index, ARDS acute respiratory distress syndrome, NMBA neuromuscular blocking agents, ICU intensive care unit

a At any time within ICU stay

Ventilator settings, lung mechanics and arterial blood gas at admission are detailed in Table 2. Mean $\mathrm{P}_{\mathrm{a}} \mathrm{O}_{2} / \mathrm{F}_{\mathrm{i}} \mathrm{O}_{2}$ was $129 \pm 52$ with total PEEP (PEEP $\left.{ }_{\text {tot }}\right) 16 \pm 3 \mathrm{cmH}_{2} \mathrm{O}$ and $\mathrm{VT}_{\mathrm{e}} 7 \pm 1.5 \mathrm{~mL} / \mathrm{kg}$ predicted body weight, generating a plateau pressure $\left(\mathrm{P}_{\text {plat }}\right)$ of $29 \pm 4 \mathrm{cmH}_{2} \mathrm{O}$ and a driving pressure $\left(\triangle P=P_{\text {plat }}-\mathrm{PEEP}_{\text {tot }}\right)$ of $13.7 \pm 4.7 \mathrm{cmH}_{2} \mathrm{O}$. Only 5 (4.9\%) patients among 15 (14.6\%) equipped, had a change in PEEP, before PP, based on esophageal pressure values. These changes were not related to the patients' position because the esophageal pressure values were similar in PP and SP. 
Table 2 Arterial blood gas, lung mechanics and volumetric capnography data during the first PP session

\begin{tabular}{|c|c|c|c|c|}
\hline Parameters & Before PP & $2 \mathrm{~h}$ after $\mathrm{PP}$ & Before SP & $2 \mathrm{~h}$ after SP \\
\hline $\mathrm{pH}$ & $7.26 \pm 0.1$ & $7.29 \pm 0.1^{\mathrm{a}}$ & $7.35 \pm 0.1^{\mathrm{a}}$ & $7.34 \pm 0.1^{\mathrm{a}}$ \\
\hline $\mathrm{P}_{\mathrm{a}} \mathrm{O}_{2}(\mathrm{mmHg})$ & $77 \pm 32$ & $99 \pm 60^{a}$ & $83 \pm 23^{a}$ & $79 \pm 23$ \\
\hline $\mathrm{P}_{\mathrm{a}} \mathrm{CO}_{2}(\mathrm{mmHg})$ & $54 \pm 13$ & $51 \pm 15^{\mathrm{a}}$ & $46 \pm 11^{\mathrm{a}}$ & $46 \pm 13^{\mathrm{a}}$ \\
\hline $\begin{array}{c}\text { Bicarbonates } \\
(\mathrm{mmol} / \mathrm{L})\end{array}$ & $23.9 \pm 5.4$ & $23.5 \pm 5.6^{a}$ & $25 \pm 5.9^{a}$ & $24.3 \pm 5.4$ \\
\hline $\mathrm{S}_{\mathrm{a}} \mathrm{O}_{2}(\%)$ & $94 \pm 3$ & $96 \pm 2^{\mathrm{a}}$ & $97 \pm 2^{\mathrm{a}}$ & $96 \pm 3^{a}$ \\
\hline RR (cycles/min) & $24 \pm 6$ & $25 \pm 6^{a}$ & $26 \pm 6^{a}$ & $26 \pm 6^{a}$ \\
\hline$V T_{\mathrm{e}}(\mathrm{mL} / \mathrm{kg} \mathrm{PBW})$ & $7 \pm 1.5$ & $7.1 \pm 1.9$ & $7.2 \pm 1.9$ & $7.1 \pm 1.7$ \\
\hline $\mathrm{F}_{\mathrm{i}} \mathrm{O}_{2}(\%)$ & $65 \pm 22$ & $54 \pm 19^{a}$ & $39 \pm 14^{a}$ & $46 \pm 17^{a}$ \\
\hline$P_{\text {plat }}\left(\mathrm{cmH}_{2} \mathrm{O}\right)$ & $29 \pm 4$ & $28 \pm 4$ & $27 \pm 3^{\mathrm{a}}$ & $27 \pm 4$ \\
\hline PEEPtot $\left(\mathrm{cmH}_{2} \mathrm{O}\right)$ & $16 \pm 3$ & $16 \pm 3$ & $15 \pm 3$ & $16 \pm 3$ \\
\hline $\mathrm{C}_{\text {stat }}\left(\mathrm{mL} / \mathrm{cmH}_{2} \mathrm{O}\right)$ & $39 \pm 16$ & $40 \pm 15$ & $44 \pm 18^{a}$ & $45 \pm 19^{a}$ \\
\hline $\mathrm{P}_{\mathrm{a}} \mathrm{O}_{2} / \mathrm{F}_{\mathrm{i}} \mathrm{O}_{2}$ & $129 \pm 52$ & $189 \pm 79^{a}$ & $237 \pm 92^{\mathrm{a}}$ & $192 \pm 79 a$ \\
\hline$\triangle P\left(\mathrm{cmH}_{2} \mathrm{O}\right)$ & $12.7 \pm 4$ & $12.3 \pm 3.9$ & $11.6 \pm 3.8^{\mathrm{a}}$ & $11.6 \pm 4.3$ \\
\hline $\mathrm{S}_{\| \mid}\left(\% \mathrm{CO}_{2} / \mathrm{L}\right)$ & $9.28 \pm 6.83$ & $8.74 \pm 8.5$ & $10.1 \pm 20.5$ & $7.05 \pm 5.18^{\mathrm{a}}$ \\
\hline $\mathrm{P}_{\mathrm{et}} \mathrm{CO}_{2}(\mathrm{mmHg})$ & $41 \pm 9$ & $39 \pm 8^{a}$ & $37 \pm 8^{\mathrm{a}}$ & $35 \pm 7^{a}$ \\
\hline $\begin{array}{l}\mathrm{VCO}_{2-\min }(\mathrm{mL} / \\
\min )\end{array}$ & $226 \pm 71$ & $232 \pm 64$ & $227 \pm 64$ & $225 \pm 62$ \\
\hline$V_{D} / V_{\text {T-phy }}(\%)$ & $36.6 \pm 8.5$ & $35.9 \pm 7.9$ & $34.9 \pm 8$ & $33.5-8^{\mathrm{a}}$ \\
\hline $\begin{array}{l}P_{(\mathrm{a}-\mathrm{et} t} \mathrm{CO}_{2} / \mathrm{P}_{\mathrm{a}} \mathrm{CO}_{2} \\
(\%)\end{array}$ & $22 \pm 16.5$ & $20.7 \pm 15.3$ & $19.5 \pm 15.1^{\mathrm{a}}$ & $20.4 \pm 17.8$ \\
\hline$V_{\mathrm{E}} \mathrm{NCO}_{2-\min }$ & $66.5 \pm 132$ & $49.2 \pm 13$ & $67.8 \pm 161^{\mathrm{a}}$ & $61.2 \pm 94.9^{\mathrm{a}}$ \\
\hline
\end{tabular}

Values are expressed with mean $\pm S D$

$R R$ respiratory rate, $C_{\text {stat }}$ static compliance, $\Delta P$ driving pressure, $S_{\text {|II }}$ phase 3 slope of volumetric capnography, $V_{\mathrm{E}}$ minute ventilation

a $p<0.05$ compared to baseline value (before PP)
The evolutions of lung mechanics, arterial blood gas and ventilator settings are specified in Table 2 and Table S1, Additional file 1 for the first PP session and in Table S2, Additional file 1 for all PP sessions combined. They globally showed similar results: a significant increase in $\mathrm{pH}$, static compliance $\left(\mathrm{C}_{\text {stat }}\right)$ and $\mathrm{P}_{\mathrm{a}} \mathrm{O}_{2} / \mathrm{F}_{\mathrm{i}} \mathrm{O}_{2}$ with a significant decrease in $\mathrm{P}_{\mathrm{a}} \mathrm{CO}_{2}, \mathrm{P}_{\text {plat }}, \mathrm{S}_{\mathrm{III}}, \mathrm{P}_{\mathrm{et}} \mathrm{CO}_{2}$, $V_{\mathrm{D}} / V_{\mathrm{T} \text {-phy }}$ and $\Delta P$. There was also an increase in mechanical power, probably secondary to slight modifications of $R R$ and inspiratory/expiratory ratio (parameters included in the formula used) [29]. The decrease in $\Delta P$ was the only parameter significantly associated with an increase in $\mathrm{P}_{\mathrm{a}} \mathrm{O}_{2} / \mathrm{F}_{\mathrm{i}} \mathrm{O}_{2}>50 \%$ (Table S3, Additional file 1).

We pooled data evolutions from the baseline (before PP) of the first session (Fig. 1) and of all PP sessions (Figure S1, Additional file 1), sampled every $30 \mathrm{~min}$. We could observe a rapid increase not only in $\mathrm{C}_{\text {dyn }}$, but also in $\mathrm{S}_{\mathrm{III}} . \Delta P_{\text {dyn }}$ and $\mathrm{P}_{\mathrm{et}} \mathrm{CO}_{2}$ decreased slightly. There was a significant decrease in $V_{\mathrm{D}} / V_{\mathrm{T} \text {-phy }}$ during the first session, but not during the pooled sessions. The pooled responder sessions to $V_{\mathrm{D}} / V_{\mathrm{T} \text {-phy }}$ (number of responder sessions $=77$ (46.7\%)), $\mathrm{S}_{\text {III }}(87(52.4 \%)), \mathrm{P}_{\mathrm{et}} \mathrm{CO}_{2}(118(61.8 \%)), \mathrm{C}_{\text {dyn }}(131$ $(73.2 \%))$ and $\Delta P_{\text {dyn }}(136(76 \%))$ showed that the beneficial physiological effect continued after $16 \mathrm{~h}$ of PP and at least up to $24 \mathrm{~h}$ which was the maximum limit for recording data (Fig. 2). When we have only looked at the first PP sessions, the response session rate was similar to that of pooled sessions: $V_{\mathrm{D}} / V_{\mathrm{T}-\text { phy }} 44(61.1 \%), \mathrm{S}_{\mathrm{III}} 47(65.3 \%)$, $\mathrm{P}_{\mathrm{et}} \mathrm{CO}_{2} 65(69.9 \%), \mathrm{C}_{\mathrm{dyn}} 62(76.5 \%)$ and $\Delta P_{\mathrm{dyn}} 65(80.2 \%)$. There were $90(91.8 \%) \mathrm{P}_{\mathrm{a}} \mathrm{O}_{2} / \mathrm{F}_{\mathrm{i}} \mathrm{O}_{2}$ responders.

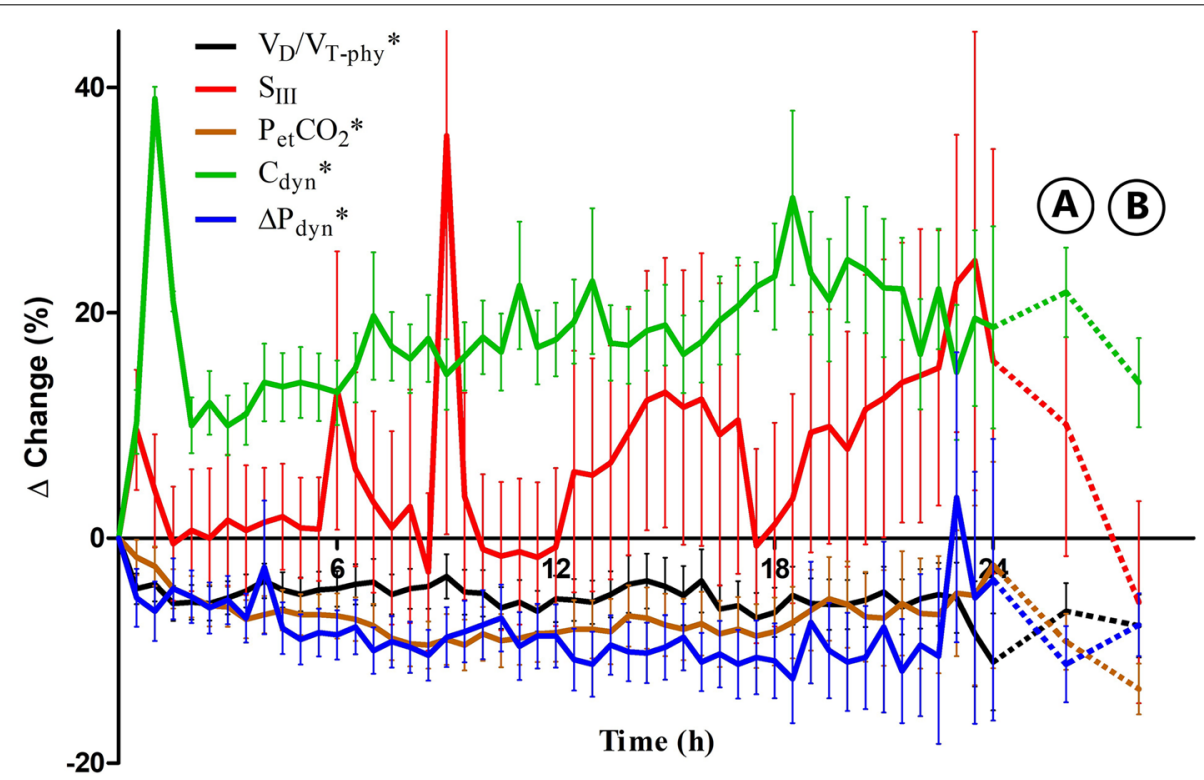

Fig. 1 Evolution of $\Delta V_{D} / V_{\text {T-phy }} \Delta S_{\| 1}, \Delta P_{\text {et }} C O_{2}$ and $\Delta C_{\text {dyn }}$ for each parameter (session 1), from $0 \mathrm{~h}$ (just before prone positioning) to $24 \mathrm{~h}$ of prone position; (A) at sessions' end (dotted line); (B) $2 \mathrm{~h}$ after return in supine position (dotted line). ${ }^{*} p<0.05$ (global time effect comparison) 


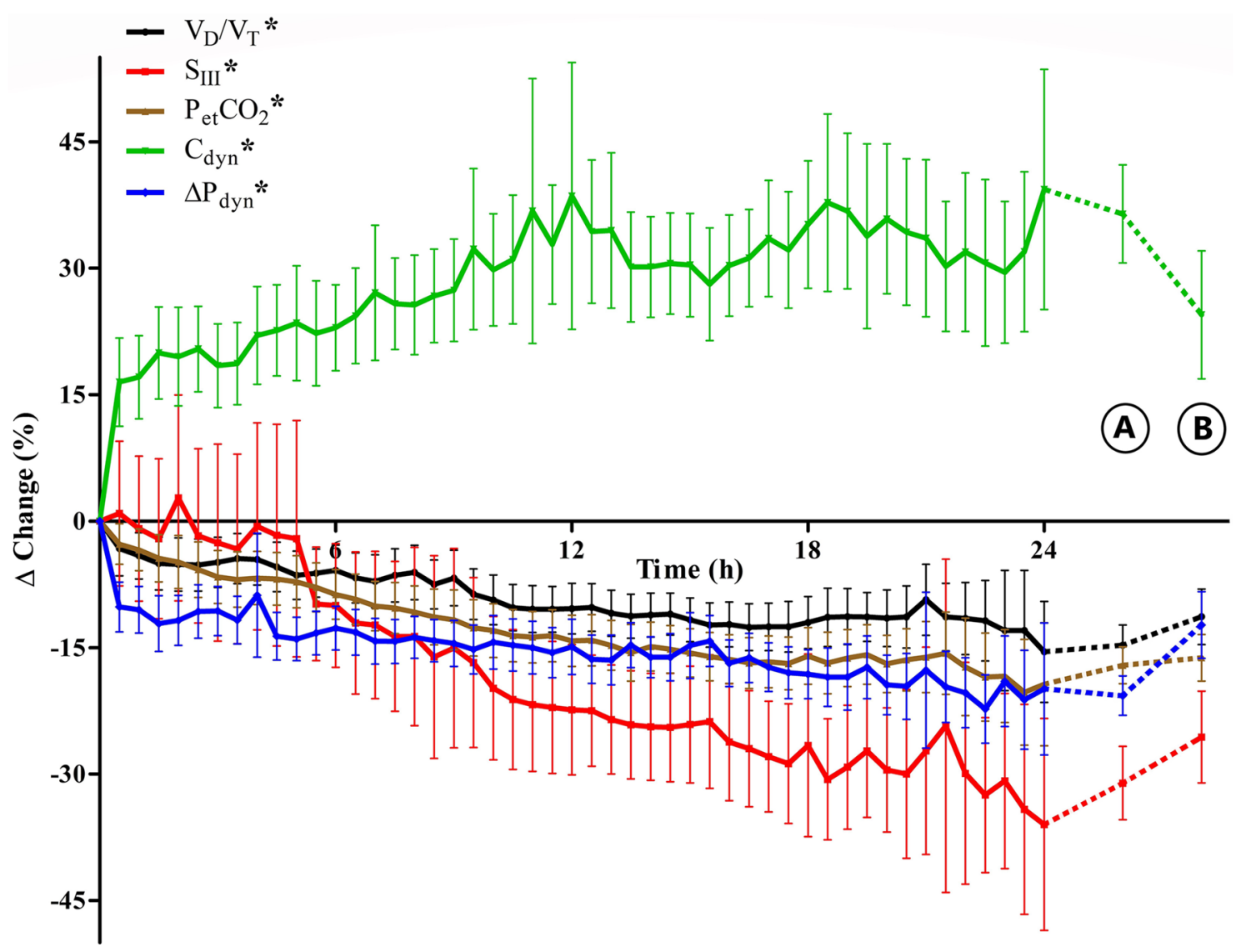

Fig. 2 Evolution of $\Delta V_{D} / V_{T-p h y} \Delta S_{\| l \mid} \Delta P_{\text {et }} C O_{2}$ and $\Delta C_{\text {dyn }}$ in responder sessions for each parameter (all sessions), from $0 \mathrm{~h}$ (just before prone positioning) to $24 \mathrm{~h}$ of prone position; (A) at sessions' end (dotted line); (B) $2 \mathrm{~h}$ after return in supine position (dotted line). ${ }^{*} p<0.05$ (global time effect comparison)

The duration of PP allowing to obtain the maximum effect was different for each parameter studied and was in median between $16 \mathrm{~h}[13,20]$ and $18[14,21]$ for all sessions, between $16 \mathrm{~h}[14,19]$ and $19[16,23]$ for responder sessions and between $17 \mathrm{~h}[13,22]$ and $18[14,21]$ for session 1 (Table S4, Additional file 1). The parameter with the higher beneficial variation was $\mathrm{C}_{\mathrm{dyn}}$ with a mean $35 \%$ increase in value for the first PP session up to $40 \%$ in $\mathrm{C}_{\mathrm{dyn}}$-responder sessions (Figs. 1, 2). Non-responder sessions are shown in Additional file 1: Figure S2.

The search of predictive criteria for mortality before prone positioning (Table S5, Additional file 1) found that higher age $(67.6 \pm 12.6$ years versus $56.7 \pm 12.1 ; p<0.001)$, higher SAPS $2(63 \pm 17$ vs $49 \pm 15, p<0.001)$, lower $C_{\text {stat }}$ $(33 \pm 14$ vs $43 \pm 16 ; p=0.003)$ and a lower minute $\mathrm{CO}_{2}$ production $\left(\mathrm{VCO}_{2-\mathrm{min}}\right)(185 \pm 81 \mathrm{~mL} / \mathrm{min}$ vs $250 \pm 53$; $p<0.001)$ were associated with mortality, whereas $\mathrm{P}_{\mathrm{a}} \mathrm{O}_{2} /$ $\mathrm{F}_{\mathrm{i}} \mathrm{O}_{2}(p=0.659), \Delta P(p=0.096)$ and $V_{\mathrm{D}} / V_{\text {T-phy }}(p=0.37)$ were not.

The evolution of the respiratory parameters during the first session, compared (without adjustment) between the survivors and the dead, did not clearly find any specific response to $\mathrm{PP}$, whether during the session or $2 \mathrm{~h}$ after the return in SP (Tables S6, S7 and S8, Additional file 1). In multivariate analysis (before PPbefore SP), the increase in $\mathrm{VCO}_{2 \text {-min }}$ (maybe mediated by the hemodynamic effects of $\mathrm{PP}$ ) and in $V_{\mathrm{D}} / V_{\mathrm{T} \text {-phy }}$ were associated with mortality (respectively, odds ratio 1.04 (95\% confidence interval 1.01; $1.07 ; p=0.015)$ and $1.03(1 ; 1.05 ; p=0.031)$ ) (Table S6, Additional file 1). In the first session (before PP-after SP), there was also a significantly greater drop in dead space among survivors $\left(\Delta V_{\mathrm{D}} / V_{\mathrm{T}-\mathrm{phy}}=-9 \%[-20 ; 0.27]\right.$ vs $-0.59 \%$ $[-11.2 ; 9.87] ; p=0.036)$. However, this effect was not found again in multivariate analysis (Table S7, Additional file 1).

It is generally observed that the parameters improving during $\mathrm{PP}$ as $\mathrm{P}_{\mathrm{a}} \mathrm{O}_{2} / \mathrm{F}_{\mathrm{i}} \mathrm{O}_{2}$ are degraded after return in SP. It could be estimated that the intensity of this relapse after return in SP is associated with excess severity or mortality of patients. However, there was no significant association between the intensity of this relapse and 
the mortality of patients in the limit of potential biases (Tables S9, Additional file 1).

We have also noticed a wide variability of response to the positioning of the respiratory parameters between each session and in the same patient. Figure 3 shows the evolution over five consecutive PP sessions of $\Delta V_{\mathrm{D}} / V_{\mathrm{T}}$ phy, $\Delta \mathrm{S}_{\mathrm{III}}, \Delta P_{\mathrm{et}} \mathrm{CO}_{2}$ and $\Delta C_{\mathrm{dyn}}$ in patient \#20 (dead) and patient \#35 (survivor). The responder or non-responder character for a parameter varied according to the patient but also according to the session and the time of the session (after $6 \mathrm{~h}, 12 \mathrm{~h}, 20 \mathrm{~h} . .$. ). In addition, for the same session, a patient could respond to one parameter but not to another. And it could be the opposite for the next session.

\section{Discussion}

Our study shows that the physiologic effects of PP increase for at least $24 \mathrm{~h}$ in some patients. It also shows that it is impossible to predict which patient will benefit from this technique before its introduction, during or even after the return in SP. The analysis of the respiratory parameters before, during and after the sessions, as well as the variability of the effect of repeated sessions in the same patient, renders the concept of PP responder lacking in physiological basis.

It has already been shown that the oxygenation gain estimated by the $\mathrm{P}_{\mathrm{a}} \mathrm{O}_{2} / \mathrm{F}_{\mathrm{i}} \mathrm{O}_{2}$ was not associated with a reduction in mortality thanks to PP [30]. It is the same for all the other parameters studied here, although previous studies have found potentially prognostic parameters such as the decrease in $\mathrm{P}_{\mathrm{a}} \mathrm{CO}_{2}[31,32]$ or alveolar dead space [32]. These results are in fact logical if one relies on the mechanism of action of prone positioning, which consists of a reduction of the VILI. PP reduces lung stress and strain by reducing the overdistention of anterior non-dependent zones while allowing recruitment of posterior dependent zones [7-9, 13, 14]. Lung expansion is more constant and homogeneous $[10,15,16]$. It should therefore be considered that putting on PP is an integral part of protective ventilation techniques such as reducing the VT. In the same way that the use of reduced current volumes should be applied until a significant improvement in ARDS allowing the reintroduction of spontaneous ventilation, PP sessions should probably be extended to a similar time. It has, again recently, been shown that the recruitment of posterior lung zones depends on the duration of positioning [33]. In our study the beneficial effect continued to increase after at least $24 \mathrm{~h}$. Interestingly, the PROSEVA study [6], the only positive randomized controlled trial, was the only one that did not stop PP therapy after a pre-established period, but continued until a significant $\left(\mathrm{P}_{\mathrm{a}} \mathrm{O}_{2} / \mathrm{F}_{\mathrm{i}} \mathrm{O}_{2}>150\right.$ in SP) and persistent $(>4 \mathrm{~h})$ improvement occurred. It would seem reasonable to continually leave patients in PP until the overall improvement of their condition allows sedation to be stopped and spontaneous ventilation to resume. Rather than repeating the sessions, it would probably be better to extend the sessions. The beneficial effect is linked to the length spent in PP, not to the maneuver per se. Also, complications during turning maneuvers are rare in experienced teams, but probably more frequent in the smallest centers. If our study did not allow us to predict a benefit in extending the sessions for more than $24 \mathrm{~h}$, it nevertheless invited us to make them last at least $24 \mathrm{~h}$. It also does not seem logical to interrupt sessions, whose initiation was motivated by a $\mathrm{P}_{\mathrm{a}} \mathrm{O}_{2} / \mathrm{F}_{\mathrm{i}} \mathrm{O}_{2}$ of less than 150, if this $\mathrm{P}_{\mathrm{a}} \mathrm{O}_{2} / \mathrm{F}_{\mathrm{i}} \mathrm{O}_{2}$ remains below 150 after $24 \mathrm{~h}$. Therefore, we suggest that the PP sessions last at least $24 \mathrm{~h}$ and be extended in the event that the $\mathrm{P}_{\mathrm{a}} \mathrm{O}_{2} / \mathrm{F}_{\mathrm{i}} \mathrm{O}_{2}$ ratio at $24 \mathrm{~h}$ remains below 150 .

Preventing ventilation-induced injuries is crucial for the future of patients with ARDS. Most of these patients die, while still on mechanical ventilation, but rarely with refractory hypoxemia [34]. It is mainly the overcomplications, the sequelae of the causal disease and the maintenance of pulmonary lesions by the mechanical ventilation which prolong the duration of invasive ventilation and are responsible for the mortality. PP should not be used as a rescue, but as a routine therapy in ARDS patients. Yet a multicenter study in 2017 found that the prevalent reason for not using PP was that hypoxemia was not considered sufficiently severe [35]. Future studies should focus on researching the benefit of PP in all ARDS patients regardless of the severity stage. There were no life-threatening complications in our cohort and they are described as rare $[6,35]$. The benefit/risk balance is therefore strongly in favor of the PP in moderate-to-severe ARDS. It should be evaluated in the mild-to-moderate ARDS. Of course, the PP session could be interrupted in the event of a serious complication or urgent care.

This study presents several limitations. First, the duration of the sessions was left free with an obligation of minimum duration of $16 \mathrm{~h}$. These lasted $21.5 \pm 5 \mathrm{~h}$ (20.722) and there was no difference in duration between surviving patients and deaths (respectively, 20.8 $\pm 3 \mathrm{~h}$ vs $21.1 \pm 6.5 ; p=0.719$ ) (Tables $\mathrm{S} 1, \mathrm{~S} 2$ and $\mathrm{S} 3$, Additional file 1). In the same way, some modifications of the ventilators' settings were allowed (RR and PEEP). This could partially explain the improvement in some studied parameters. As Tables S1, S2 and S3, Additional file 1 show, these changes may be statistically significant but are not clinically relevant. They cannot explain the observed evolution of physiological parameters by themselves. The design of the study does not allow, without a control group, to affirm that the physiological effects studied are solely due to PP and not to the evolution of the disease. Especially since part of the effect is "lost" 

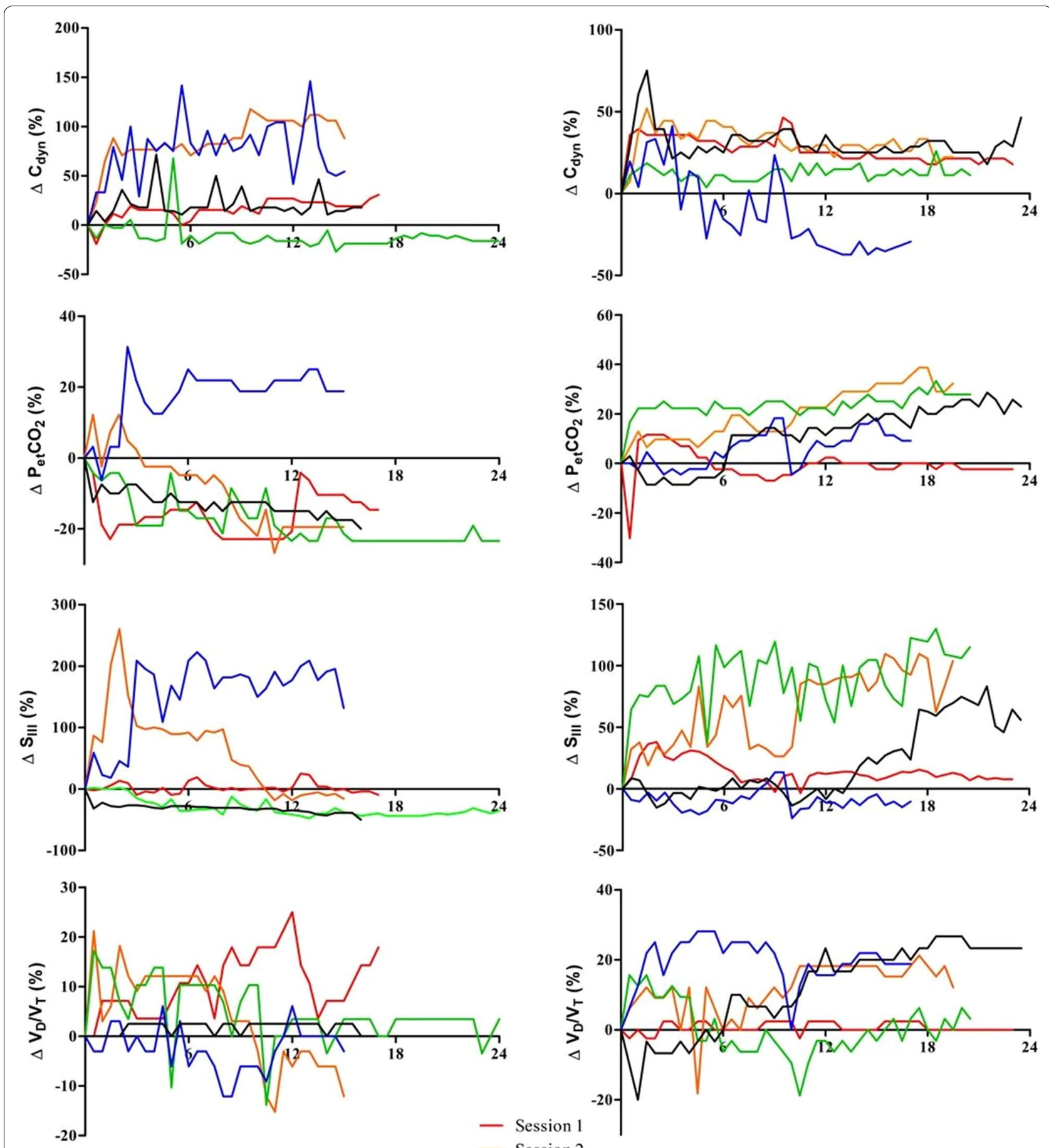

Time (h)

- Session 2

- Session 3

- Session 4

Patient \# 20 - Dead

- Session 5

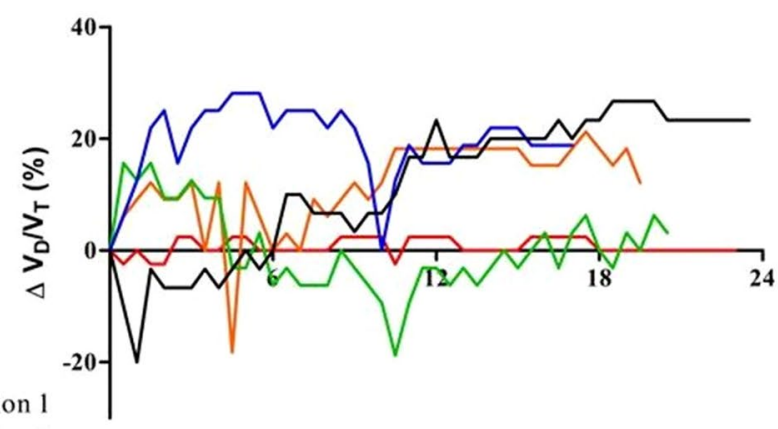

Time (h)

Fig. 3 Evolution over five consecutive prone position sessions of $\Delta C_{\text {dyn, }} \Delta P_{\mathrm{et}} C_{2}, \Delta \mathrm{S}_{\| \mid}$and $\Delta V_{D} / V_{\text {T-phy }}$ in patient \#20 (dead) and patient \#35 (survivor), from $0 \mathrm{~h}$ (just before prone positioning) to the end of each prone position session 
after the return to SP. This effect is really related to $\mathrm{PP}$ for $\mathrm{P}_{\mathrm{a}} \mathrm{O}_{2} / \mathrm{F}_{\mathrm{i}} \mathrm{O}_{2}$ [6], for $\mathrm{pH}$ and $\mathrm{RR}$ (therefore for $\mathrm{P}_{\mathrm{a}} \mathrm{CO}_{2}$ ) [4] and therefore also for the other studied parameters that evolved very significantly over short periods.

The absence of randomization meant that the analysis of the factors potentially associated with mortality was marred by many potential biases. It was an observational study and these results should be interpreted with caution.

Another major limitation concerns the population studied. These were mainly patients with ARDS secondary to pneumonia complicated by septic shock. It is possible to say that the results could have been different with extrapulmonary ARDS [36] or with less shocked patients. However, this would not change the logic of leaving patients in PP to reduce the risk of VILI.

Anatomical or functional alveolar recruitability has not been evaluated. It would be an interesting parameter to evaluate in the effects of PP. Finally, the hemodynamic impact of PP has not been studied except via $\mathrm{VCO}_{2 \text {-min }}$ and $\mathrm{P}_{(\text {a-et })} \mathrm{CO}_{2}$. Indeed our study found an association between mortality and low $\mathrm{CO}_{2}$ production. It was probably linked to a defect in cellular perfusion from circulatory failure. $101(98.1 \%)$ of the patients were on vasopressors. This aspect is probably major, at least in patients with acute cor pulmonale [37, 38]. More studies are needed on this topic. In addition, the volumetric capnography data are significantly affected by the hemodynamic state of the patient, which makes their interpretation more difficult.

\section{Conclusions}

In conclusion, the maximum physiological response to PP requires in some patients at least $24 \mathrm{~h}$ of positioning. It is not possible to predict which patient will benefit from PP before, during, or even after the maneuver. Therefore, we suggest that the PP sessions last at least $24 \mathrm{~h}$ and be extended in the event that the $\mathrm{P}_{\mathrm{a}} \mathrm{O}_{2} / \mathrm{F}_{\mathrm{i}} \mathrm{O}_{2}$ ratio at $24 \mathrm{~h}$ remains below 150. In the event of a relapse of the $\mathrm{P}_{\mathrm{a}} \mathrm{O}_{2} /$ $\mathrm{F}_{\mathrm{i}} \mathrm{O}_{2}$ ratio below 150 after putting back in supine position, a new session of at least $24 \mathrm{~h}$ of PP should be carried out, and so on until the moment of deciding to stop sedation and resume spontaneous ventilation. PP should be integrated into the protective ventilation of moderateto-severe ARDS in the same way as the reduction in tidal volume.

\section{Supplementary information}

Supplementary information accompanies this paper at https://doi. org/10.1186/s13613-020-00683-7.

Additional file 1. Additional figures and tables.

\section{Abbreviations}

ARDS: Acute respiratory distress syndrome; $B M I$ : Body mass index; $C_{\text {dyn }}$ Dynamic compliance; $C_{\text {stat: }}$ Static compliance; $\triangle P$ : Driving pressure; $\Delta P_{\text {dyn }}$ : Dynamic driving pressure; ECMO: Extracorporeal membrane oxygenation; ICU: Intensive care unit; NMBA: Neuromuscular blocking agent; $\mathrm{P}_{(\text {a-et) }} \mathrm{CO}_{2}$ : Difference between arterial and end-tidal $\mathrm{CO}_{2}$ pressures; PBW: Predicted body weight; PEEP tot: Total PEEP; $\mathrm{P}_{\mathrm{et}} \mathrm{CO}_{2}$ : End tidal $\mathrm{CO}_{2}$ pressure; PP: Prone position; $P_{\text {plat }}$ : Plateau pressure; RR: Respiratory rate; $S_{\| 1:}$ : Phase 3 slope of volumetric capnography; SAPS 2: Simplified Acute Physiologic Score 2; SOFA: Sepsis-related Organ Failure Assessment; $\mathrm{SP}$ : Supine position; $\mathrm{VCO}_{2-\text { min }}: \mathrm{CO}_{2}$ production per minute; $V_{D} / V_{\text {T-phy: }}:$ Physiological Bohr dead space; $V_{\mathrm{E}}:$ Minute ventilation; VILI: Ventilator-induced lung injury; $V T$ : Tidal volume; $V_{\mathrm{e}}$ : Expiratory tidal volume.

\section{Acknowledgements}

We thank Charles Timoney for his corrections of the manuscript.

\section{Site of study, data property and sharing, reprints}

The study has been performed in the Département de Médecine IntensiveRéanimation, GH Sud lle-de-France, Melun, France. The corresponding author has full access to all the data in the study and is responsible for publication.

Requests for reprints should be made to the corresponding author.

\section{Authors' contributions}

SJ had the original idea. SJ performed study design and administrative authorizations. All authors included patients and collected data. SJ and MM performed statistical analysis. SJ wrote the manuscript, the figures and tables. All authors analyzed and discussed the results. All authors read and approved the final manuscript.

\section{Funding}

No external funding.

\section{Availability of data and materials}

Deidentified patients' datasets used and/or analyzed during the current study are available from the corresponding author on reasonable request.

\section{Ethics approval and consent to participate}

The study protocol has been approved by the Institutional Review Board of the French learned society for respiratory medicine (Société de Pneumologie de Langue Française) in accordance with the ethical standards laid down in the 1964 Declaration of Helsinki and its later amendments. Patients, or their relatives, have consented to the use of the data.

\section{Consent for publication}

Patients, or their relatives, have consented to the use of the data.

\section{Competing interests}

SJ and JC received fees for lectures from Hamilton Medical ${ }^{\circledR}$. Remaining authors have disclosed that they have no conflict of interest.

\section{Author details}

'Département de Médecine Intensive-Réanimation, GH Sud lle-de-France, Hôpital de Melun, 270 avenue Marc Jacquet, 77000 Melun, France. ${ }^{2}$ Unité de Recherche Clinique, GH Sud Ile-de-France, Hôpital de Melun, 270 avenue Marc Jacquet, 77000 Melun, France. ${ }^{3}$ Service de Réanimation Médicale, AP-HP, Hôpital Saint-Antoine, 184 rue du Faubourg Saint-Antoine, 75012 Paris, France. ${ }^{4}$ Service de Réanimation, Hôpital de Béthune, 27 rue Delbecque, 62660 Beuvry, France.

Received: 8 November 2019 Accepted: 16 May 2020

Published online: 24 May 2020

\section{References}

1. Pappert D, Rossaint R, Slama K, Grüning T, Falke KJ. Influence of positioning on ventilation-perfusion relationships in severe adult respiratory distress syndrome. Chest. 1994;106:1511-6.

2. Gattinoni L, Tognoni G, Pesenti A, Taccone P, Mascheroni D, Labarta V, et al. Effect of prone positioning on the survival of patients with acute respiratory failure. N Engl J Med. 2001;345:568-73. 
3. Guerin C, Gaillard S, Lemasson S, Ayzac L, Girard R, Beuret P, et al. Effects of systematic prone positioning in hypoxemic acute respiratory failure: a randomized controlled trial. JAMA. 2004;292:2379-87.

4. Mancebo J, Fernández R, Blanch L, Rialp G, Gordo F, Ferrer M, et al. A multicenter trial of prolonged prone ventilation in severe acute respiratory distress syndrome. Am J Respir Crit Care Med. 2006;173:1233-9.

5. Taccone P, Pesenti A, Latini R, Polli F, Vagginelli F, Mietto C, et al. Prone positioning in patients with moderate and severe acute respiratory distress syndrome: a randomized controlled trial. JAMA. 2009:302:1977-84.

6. Guérin C, Reignier J, Richard J-C, Beuret P, Gacouin A, Boulain T, et al. Prone positioning in severe acute respiratory distress syndrome. N Engl J Med. 2013:368:2159-68.

7. Cornejo RA, Díaz JC, Tobar EA, Bruhn AR, Ramos CA, González RA, et al. Effects of prone positioning on lung protection in patients with acute respiratory distress syndrome. Am J Respir Crit Care Med. 2013;188:440-8.

8. Galiatsou E, Kostanti E, Svarna E, Kitsakos A, Koulouras V, Efremidis SC, et al. Prone position augments recruitment and prevents alveolar overinflation in acute lung injury. Am J Respir Crit Care Med. 2006;174:187-97.

9. Mentzelopoulos SD, Roussos C, Zakynthinos SG. Prone position reduces lung stress and strain in severe acute respiratory distress syndrome. Eur Respir J. 2005;25:534-44.

10. Richter T, Bellani G, Scott Harris R, Vidal Melo MF, Winkler T, Venegas JG, et al. Effect of prone position on regional shunt, aeration, and perfusion in experimental acute lung injury. Am J Respir Crit Care Med. 2005;172:480-7.

11. Vieillard-Baron A, Rabiller A, Chergui K, Peyrouset O, Page B, Beauchet $A$, et al. Prone position improves mechanics and alveolar ventilation in acute respiratory distress syndrome. Intensive Care Med. 2005;31:220-6.

12. Kumaresan A, Gerber R, Mueller A, Loring SH, Talmor D. Effects of Prone Positioning on Transpulmonary Pressures and End-expiratory Volumes in Patients without Lung Disease. Anesthesiol J Am Soc Anesthesiol. 2018. http://anesthesiology.pubs.asahq.org/article.aspx?articleid=2674902. Accessed 29 Mar 2018.

13. Valenza F, Guglielmi M, Maffioletti M, Tedesco C, Maccagni P, Fossali T, et al. Prone position delays the progression of ventilator-induced lung injury in rats: does lung strain distribution play a role? Crit Care Med. 2005;33:361-7.

14. Broccard A, Shapiro RS, Schmitz LL, Adams AB, Nahum A, Marini JJ. Prone positioning attenuates and redistributes ventilator-induced lung injury in dogs. Crit Care Med. 2000;28:295-303.

15. Mure M, Domino KB, Lindahl SG, Hlastala MP, Altemeier WA, Glenny RW. Regional ventilation-perfusion distribution is more uniform in the prone position. J Appl Physiol Bethesda Md. 1985;2000(88):1076-83.

16. Henderson AC, Sá RC, Theilmann RJ, Buxton RB, Prisk GK, Hopkins SR. The gravitational distribution of ventilation-perfusion ratio is more uniform in prone than supine posture in the normal human lung. J Appl Physiol Bethesda Md. 1985:2013(115):313-24.

17. Sud S, Friedrich JO, Taccone P, Polli F, Adhikari NKJ, Latini R, et al. Prone ventilation reduces mortality in patients with acute respiratory failure and severe hypoxemia: systematic review and meta-analysis. Intensive Care Med. 2010;36:585-99.

18. Gattinoni L, Carlesso E, Taccone P, Polli F, Guérin C, Mancebo J. Prone positioning improves survival in severe ARDS: a pathophysiologic review and individual patient meta-analysis. Minerva Anestesiol. 2010;76:448-54.

19. The Acute Respiratory Distress Syndrome Network. Ventilation with lower tidal volumes as compared with traditional tidal volumes for acute lung injury and the acute respiratory distress syndrome. N Engl J Med. 2000;342:1301-8.

20. Papazian L, Forel J-M, Gacouin A, Penot-Ragon C, Perrin G, Loundou A, et al. Neuromuscular blockers in early acute respiratory distress syndrome. N Engl J Med. 2010;363:1107-16.

21. Moss M, Huang DT, Brower RG, Ferguson ND, Ginde AA, et al. National Heart, Lung, and Blood Institute PETAL clinical trials network, early neuromuscular blockade in the acute respiratory distress syndrome. N Engl J Med. 2019;380:1997-2008.
22. Yoshida T, Kavanagh BP, Brochard L. Early neuromuscular blockade in the acute respiratory distress syndrome. N Engl J Med. 2019;381:786-7.

23. Fan E, Del Sorbo L, Goligher EC, Hodgson CL, Munshi L, Walkey AJ, et al. An Official American Thoracic Society/European Society of Intensive Care Medicine/Society of Critical Care Medicine Clinical Practice Guideline: mechanical ventilation in adult patients with acute respiratory distress syndrome. Am J Respir Crit Care Med. 2017:195:1253-63.

24. Papazian L, Aubron C, Brochard L, Chiche J-D, Combes A, Dreyfuss D, et al. Formal guidelines: management of acute respiratory distress syndrome. Ann Intensive Care. 2019;9:69.

25. Albert RK. Prone ventilation for patients with mild or moderate ARDS. Ann Am Thorac Soc. 2019;17(1):24-9.

26. Mercat A, Richard J-CM, Vielle B, Jaber S, Osman D, Diehl J-L, et al. Positive end-expiratory pressure setting in adults with acute lung injury and acute respiratory distress syndrome: a randomized controlled trial. JAMA. 2008:299:646-55.

27. Blanch L, Romero PV, Lucangelo U. Volumetric capnography in the mechanically ventilated patient. Minerva Anestesiol. 2006;72:577-85.

28. Ranieri VM, Rubenfeld GD, Thompson BT, Ferguson ND, Caldwell E, ARDS Definition Task Force, et al. Acute respiratory distress syndrome: the Berlin definition. JAMA. 2012;307:2526-33.

29. Gattinoni L, Tonetti T, Cressoni M, Cadringher P, Herrmann P, Moerer O, et al. Ventilator-related causes of lung injury: the mechanical power. Intensive Care Med. 2016;42:1567-75.

30. Albert RK, Keniston A, Baboi L, Ayzac L, Guérin C, Proseva Investigators. Prone position-induced improvement in gas exchange does not predict improved survival in the acute respiratory distress syndrome. Am J Respir Crit Care Med. 2014;189:494-6.

31. Gattinoni L, Vagginelli F, Carlesso E, Taccone P, Conte V, Chiumello D, et al. Decrease in $\mathrm{PaCO} 2$ with prone position is predictive of improved outcome in acute respiratory distress syndrome. Crit Care Med. 2003;31:2727-33.

32. Charron C, Repesse X, Bouferrache K, Bodson L, Castro S, Page B, et al. $\mathrm{PaCO} 2$ and alveolar dead space are more relevant than $\mathrm{PaO} 2 / \mathrm{FiO}_{2}$ ratio in monitoring the respiratory response to prone position in ARDS patients: a physiological study. Crit Care Lond Engl. 2011;15:R175.

33. Mezidi M, Parrilla FJ, Yonis H, Riad Z, Böhm SH, Waldmann AD, et al. Effects of positive end-expiratory pressure strategy in supine and prone position on lung and chest wall mechanics in acute respiratory distress syndrome. Ann Intensive Care. 2018:8:86.

34. Briel M, Meade M, Mercat A, Brower RG, Talmor D, Walter SD, et al. Higher vs lower positive end-expiratory pressure in patients with acute lung injury and acute respiratory distress syndrome: systematic review and meta-analysis. JAMA. 2010;303:865-73.

35. Guérin C, Beuret P, Constantin JM, Bellani G, Garcia-Olivares P, Roca O, et al. A prospective international observational prevalence study on prone positioning of ARDS patients: the APRONET (ARDS Prone Position Network) study. Intensive Care Med. 2017;44(1):22-37.

36. Lim CM, Kim EK, Lee JS, Shim TS, Lee SD, Koh Y, et al. Comparison of the response to the prone position between pulmonary and extrapulmonary acute respiratory distress syndrome. Intensive Care Med. 2001;27:477-85.

37. Jozwiak M, Teboul J-L, Anguel N, Persichini R, Silva S, Chemla D, et al. Beneficial hemodynamic effects of prone positioning in patients with acute respiratory distress syndrome. Am J Respir Crit Care Med. 2013;188:1428-33.

38. Vieillard-Baron A, Charron C, Caille V, Belliard G, Page B, Jardin F. Prone positioning unloads the right ventricle in severe ARDS. Chest. 2007;132:1440-6.

\section{Publisher's Note}

Springer Nature remains neutral with regard to jurisdictional claims in published maps and institutional affiliations. 